\title{
Article \\ Amyotrophic Lateral Sclerosis Risk, Family Income, and Fish Consumption Estimates of Mercury and Omega-3 PUFAs in the United States
}

\author{
Hannah I. Hoffman ${ }^{1}(\mathbb{D})$, Walter G. Bradley ${ }^{2}\left(\mathbb{D}\right.$, Celia Y. Chen ${ }^{1}$, Erik P. Pioro ${ }^{3} \mathbb{D}$, Elijah W. Stommel ${ }^{4}$ and $^{2}$ \\ Angeline S. Andrew 4,*(D) \\ 1 Department of Biological Sciences, Dartmouth College, Hanover, NH 03755, USA; \\ hoffmanh@mit.edu (H.I.H.); celia.y.chen@dartmouth.edu (C.Y.C.) \\ 2 Department of Neurology, Miller School of Medicine, University of Miami, Miami, FL 33146, USA; \\ w.bradley@med.miami.edu \\ 3 ALS and Neuromuscular Disease Center, Cleveland Clinic, Cleveland, OH 44195, USA; pioroe@ccf.org \\ 4 Department of Neurology, Geisel School of Medicine, Lebanon, NH 03756, USA; \\ Elijah.W.Stommel@hitchcock.org \\ * Correspondence: Angeline.Andrew@dartmouth.edu; Tel.: +1-603-653-9019
}

check for

updates

Citation: Hoffman, H.I.; Bradley, W.G.; Chen, C.Y.; Pioro, E.P.; Stommel, E.W.; Andrew, A.S. Amyotrophic Lateral Sclerosis Risk, Family Income, and Fish Consumption Estimates of Mercury and Omega-3 PUFAs in the United States. Int. J. Environ. Res. Public Health 2021, 18, 4528. https:// doi.org/10.3390/ijerph18094528

Academic Editors: Paul Tchounwou and Jun Yoshinaga

Received: 18 March 2021

Accepted: 21 April 2021

Published: 24 April 2021

Publisher's Note: MDPI stays neutra with regard to jurisdictional claims in published maps and institutional affiliations.

Copyright: (c) 2021 by the authors. Licensee MDPI, Basel, Switzerland. This article is an open access article distributed under the terms and conditions of the Creative Commons Attribution (CC BY) license (https:// creativecommons.org/licenses/by/ $4.0 /)$

\begin{abstract}
Most amyotrophic lateral sclerosis (ALS) cases are considered sporadic, without a known genetic basis, and lifestyle factors are suspected to play an etiologic role. We previously observed increased risk of ALS associated with high nail mercury levels as an exposure biomarker and thus hypothesized that mercury exposure via fish consumption patterns increases ALS risk. Lifestyle surveys were obtained from ALS patients $(n=165)$ and $n=330$ age- and sex-matched controls without ALS enrolled in New Hampshire, Vermont, or Ohio, USA. We estimated their annual intake of mercury and omega-3 polyunsaturated fatty acid (PUFA) via self-reported seafood consumption habits, including species and frequency. In our multivariable model, family income showed a significant positive association with ALS risk $(p=0.0003$, adjusted for age, sex, family history, education, and race). Neither the estimated annual mercury nor omega-3 PUFA intakes via seafood were associated with ALS risk. ALS incidence is associated with socioeconomic status; however, consistent with a prior international study, this relationship is not linked to mercury intake estimated via fish or seafood consumption patterns.
\end{abstract}

Keywords: amyotrophic lateral sclerosis; mercury; omega-3 fatty acids; fish; neuromuscular disease

\section{Introduction}

Amyotrophic lateral sclerosis (ALS) is a progressive neurological disease that damages motor neurons and can induce severe disability. While approximately $10 \%$ of patients inherit forms of ALS that are familial, lifestyle and environmental factors likely play a role in many cases [1]. We previously used biomarkers in toenail and fingernail tissue to link mercury exposure to increased risk of ALS in two independent U.S. cohorts [2,3]. The source of this mercury exposure remains unclear.

While mercury is thought to be a risk factor for the disease, omega-3 polyunsaturated fatty acids (PUFA) could be protective factors against ALS, as food frequency questionnaire estimates showed that omega-3 PUFA intake was associated with reduced risk in a large prospective cohort analysis [4]. The leading source of both mercury and omega-3 PUFA exposure in the United States is seafood consumption, as seafood species concentrate chemicals in their viscera and muscle tissue through ingestion of algae and seafood species in lower trophic levels [5-8]. Humans retain up to $95 \%$ of these chemicals per bite of seafood [9]. Therefore, we hypothesized that the source of the mercury that is associated with increased risk of ALS could be seafood. Since omega-3 PUFA might be protective against the effect of mercury, we assessed the intake of omega-3 PUFA via seafood. Also, 
in a nationally distributed control cohort, we observed previously that the toenail mercury levels were positively associated with income level, with a mean per-person household income of $\sim \$ 56,000$ for those in the top decile for toenail mercury, vs. $\sim \$ 38,000$ for those with lower mercury levels [3]. We then postulated that fish consumption patterns, particularly, frequent consumption of costly high-trophic level species that have high levels of mercury may be linked to ALS risk. Hence, we investigated the links between ALS and socioeconomic status and mercury intake via fish consumption.

Using demographic and seafood consumption questionnaire data from participants in our case-control studies in Northern New England and Ohio, we assessed the relationship between socioeconomic status, estimated mercury, and omega-3 PUFA intake and ALS risk.

\section{Materials and Methods}

\subsection{ALS Patients}

Were enrolled through medical centers and clinics in New Hampshire, Vermont, and Ohio, as described previously [10]. Participants were required to be at least 21 years of age and residents of Northern New England or Ohio (comprising the states of New Hampshire, Vermont, Maine, or Ohio) at the time of enrollment (2016-2020). The eligible ALS patients were newly diagnosed cases with either definite or probable ALS according to the Awajimodified El Escorial criteria [11]. Eligible diagnoses included progressive bulbar palsy, but not primary muscular atrophy (PMA) or primary lateral sclerosis (PLS).

\subsection{The Population-Control Participants}

Selected from among the same catchment counties as the cases, were identified as residents of New Hampshire, Vermont, or Ohio using the U.S. Postal Service Delivery Sequence file licensed to Marketing Systems Group (Horsham, PA, USA). The sampling algorithm was designed based on the expected demographic distribution of the ALS cases, with over-sampling of males and 50-75-year-old subjects. Questionnaires were mailed out to the sampled individuals, followed by a postcard reminder. Questionnaire response rates were $56 \%$ for ALS patients and $10 \%$ for the population controls. Participants who returned a completed questionnaire received a $\$ 20$ reimbursement. Participants consented to join the study. All study procedures were approved by the local human subjects protection committees at each contributing institution.

We used the R-package "MatchIt" to perform propensity score matching with a 2:1 ratio to select a subset of $n=330$ population control questionnaires as a comparison group with a similar age and gender distribution to that of the ALS cases group ( $n=165$ Awaji definite or probable) [12]. This procedure selects two controls with the nearest age and same gender as each case.

\subsection{Estimating Mercury Consumption}

We used these surveys to estimate the annual mercury consumption among seafood consumers by cross-referencing self-reported consumption of seafood by type with the corresponding species-specific mean mercury concentrations and multiplying this value by the consumption frequency. Fish or seafood type was recorded in a free response chart, broken down into those types consumed weekly, monthly, or annually. Species-specific mean mercury concentrations were primarily based on previously published U.S. market means [13-20]. Several fish species required consulting additional sources to obtain a mercury concentration value [21-24].

\subsection{Estimating Omega-3 PUFA Consumption}

We also used published U.S. market surveys to estimate the annual omega-3 PUFA consumption among seafood consumers with a similar tactic: cross-referencing self-reported consumption of seafood by type with the corresponding species-specific mean omega-3 PUFA concentrations and multiplying this value by the consumption frequency (recorded as weekly, monthly, or annually) [23-28]. Species-specific mean omega-3 PUFA concentra- 
tions were primarily based on U.S. market means (Supplemental Table S1). Several species required consulting additional omega-3 PUFA concentration references (Supplementary Table S2).

\subsection{Statistical Analysis}

We started by testing for univariate associations between the response variable, ALS case-control status of participants, and categorical predictor variables by utilizing the chi-square test of independence and Fisher's exact test. Multivariable modeling used case-control status as the outcome in an unconditional logistic regression analysis with adjustment for the potential confounders age, gender, family history, and smoking status. The index year was defined as the year of diagnosis for ALS patients or an equivalent year for controls. Bayesian Kernal Mixture Modeling (BKMR) was performed to assess the possible interactions between income, mercury, and omega-3 PUFA estimates [29]. These analyses were all performed using R: A Language and Environment for Statistical Computing, version 4.02 (R Foundation for Statistical Computing, Vienna, Austria).

\subsection{Data Availability}

The database tabulating mean mercury and omega-3 polyunsaturated fatty acid (PUFA) concentrations in seafoods is provided in Supplemental Table S1.

\section{Results}

ALS patients $(n=165)$ and their 2:1 matched controls were similar for age, gender, race, smoking, as well as educational attainment (Table 1). Approximately half of the ALS patients were in the age range of 50-65 years. ALS was present in the family history of $10.9 \%$ of the patients and almost none of the controls $(p<0.001)$. All ALS patients met the Awaji criteria for definite or probable ALS. Approximately $50 \%$ of the population reported consuming fish regularly (at least 15 times a year), and this overall consumption was not associated with ALS risk $(p=0.68)$.

Table 1. Characteristics of ALS cases and controls.

\begin{tabular}{|c|c|c|c|c|}
\hline \multirow{2}{*}{ Characteristic } & \multirow{2}{*}{ Category } & Controls & ALS Cases & Univariate \\
\hline & & $n=330(\%)$ & $n=165(\%)$ & $p$-Value \\
\hline \multirow[t]{2}{*}{ Sex } & female & $132(40.0)$ & $71(43.0)$ & 0.58 \\
\hline & male & $198(60.0)$ & $94(57.0)$ & \\
\hline \multirow[t]{4}{*}{ Age } & $<50$ & $23(7.0)$ & $13(7.9)$ & 0.96 \\
\hline & $50-65$ & $159(48.2)$ & $76(46.1)$ & \\
\hline & $65-75$ & $115(34.8)$ & $58(35.2)$ & \\
\hline & $75+$ & $33(10.0)$ & $18(10.9)$ & \\
\hline \multirow[t]{2}{*}{ ALS family history } & no & $323(97.9)$ & 147 (89.1) & $<0.001$ \\
\hline & 1st or 2 nd degree & $7(2.1)$ & $18(10.9)$ & \\
\hline \multirow[t]{2}{*}{ Race } & non-white & $29(8.8)$ & $16(9.7)$ & 0.87 \\
\hline & white & 301 (91.2) & $149(90.3)$ & \\
\hline \multirow[t]{3}{*}{ Awaji criteria } & none & $330(100.0)$ & $0(0.0)$ & \\
\hline & definite & & $81(49.1)$ & \\
\hline & probable & & $84(50.9)$ & \\
\hline \multirow[t]{2}{*}{ Smoking } & ever & $154(47.1)$ & $90(56.6)$ & 0.061 \\
\hline & never & 173 (52.9) & $69(43.4)$ & \\
\hline \multirow[t]{5}{*}{ Education } & $\leq$ high school & $107(32.8)$ & $62(40.3)$ & 0.64 \\
\hline & tech & $40(12.3)$ & 17 (11.0) & \\
\hline & college & $99(30.4)$ & $41(26.6)$ & \\
\hline & postgrad & $57(17.5)$ & $24(15.6)$ & \\
\hline & other & $23(7.1)$ & $10(6.5)$ & \\
\hline \multirow[t]{5}{*}{ Income } & $<\$ 40,000$ & $132(29.4)$ & $39(24.2)$ & 0.24 \\
\hline & $\$ 40-60,000$ & $92(20.5)$ & $26(16.1)$ & \\
\hline & $\$ 60-80,000$ & $62(13.8)$ & $23(14.3)$ & \\
\hline & $\$ 80-150,000$ & $109(24.3)$ & $45(28.0)$ & \\
\hline & $\$ 150,000+$ & $54(12.0)$ & $28(17.4)$ & \\
\hline \multirow[t]{2}{*}{ Consume fish } & no & $170(51.5)$ & $79(49.1)$ & 0.68 \\
\hline & yes & $160(48.5)$ & $82(50.9)$ & \\
\hline
\end{tabular}


Table 2 shows the multivariable model we constructed, containing age, sex, smoking, family history, family income, education, and race. Family history of ALS increased risk of ALS nearly 4-fold. A family income $\$ 150,000$ or over was associated with a 2-fold higher risk of ALS, compared to those in the $\$ 60-80,000$ income bracket.

Table 2. Multivariable model of demographic/lifestyle factors and ALS risk.

\begin{tabular}{cccccc}
\hline Multivariable Model & Category & $p$-Value & OR & 95\% CI & \\
\hline Smoking & Ever & & $1.0(\mathrm{ref})$ & & \\
& never & 0.52 & 0.88 & $0.59-$ & 1.30 \\
ALS family history & No & & $1.0(\mathrm{ref})$ & & \\
& 1st or 2 nd degree & 0.0010 & 3.93 & $1.74-$ & 9.08 \\
Family income & $<\$ 40,000$ & 0.078 & 0.55 & $0.28-$ & 1.08 \\
& $\$ 40-60,000$ & 0.21 & 0.64 & $0.32-$ & 1.28 \\
& $\$ 60-80,000$ & & $1.0(\mathrm{ref})$ & & \\
& $\$ 80-150,000$ & 0.60 & 1.18 & $0.64-$ & 2.22 \\
& $\$ 150,000+$ & 0.046 & 2.09 & $1.02-$ & 4.34 \\
Education & $\leq$ high school & & $1.0(\mathrm{ref})$ & & \\
& technical school & 0.38 & 0.74 & $0.37-$ & 1.43 \\
& college & 0.12 & 0.67 & $0.39-$ & 1.12 \\
& graduate school & 0.06 & 0.55 & $0.29-$ & 1.02 \\
& Other & 0.43 & 0.72 & $0.30-$ & 1.61 \\
& non-white & & $1.0(\mathrm{ref})$ & & \\
& White & 0.90 & 0.94 & $0.42-$ & 2.36 \\
\hline
\end{tabular}

* Adjusted for age, sex, and all factors shown in the table.

In contrast, family income was positively associated with risk of ALS, increasing $23 \%$ for every $\$ 20,000$ in income through $\$ 80,000$ (OR 1.23 95\% CI 1.10-1.38, adjusted for age, sex, family history, education, and race) (Figure 1).

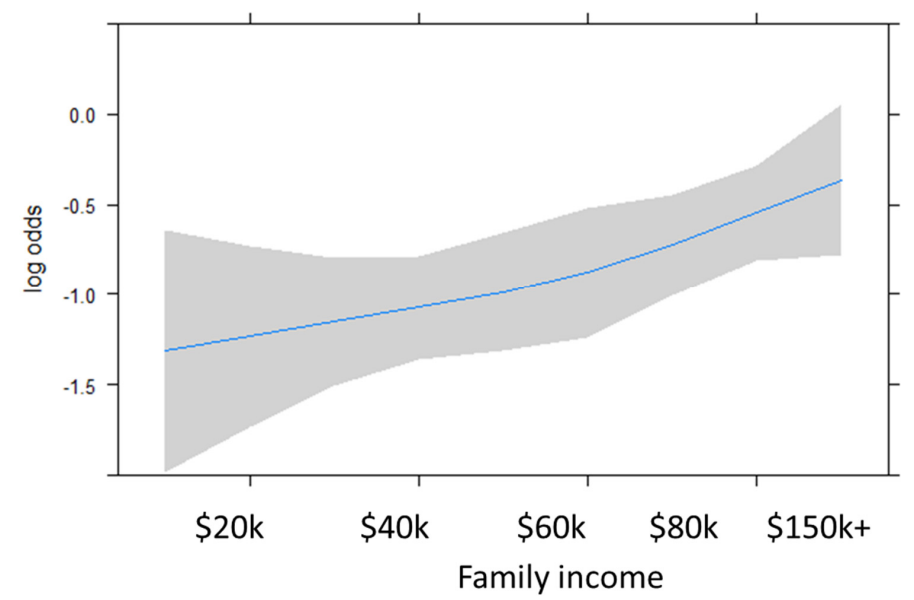

Figure 1. Spline model depicting the risk of ALS by family income $(p=0.00030)$. Blue line represents the log odds and the grey shading depicts the $95 \%$ CI.

We used a fish-consumption questionnaire to estimate the annual intake of mercury and omega-3 PUFA by multiplying the content of a typical fish of each species by the frequency. Figure 2 shows the relationship between mercury and omega-3 PUFA content by fish type. The two are generally co-occurring, with only a few outlying species (e.g., swordfish) having very high mercury content, but low omega-3 PUFA. Whitefish, salmon and herring have the lowest mercury content, but high omega-3 PUFA. 


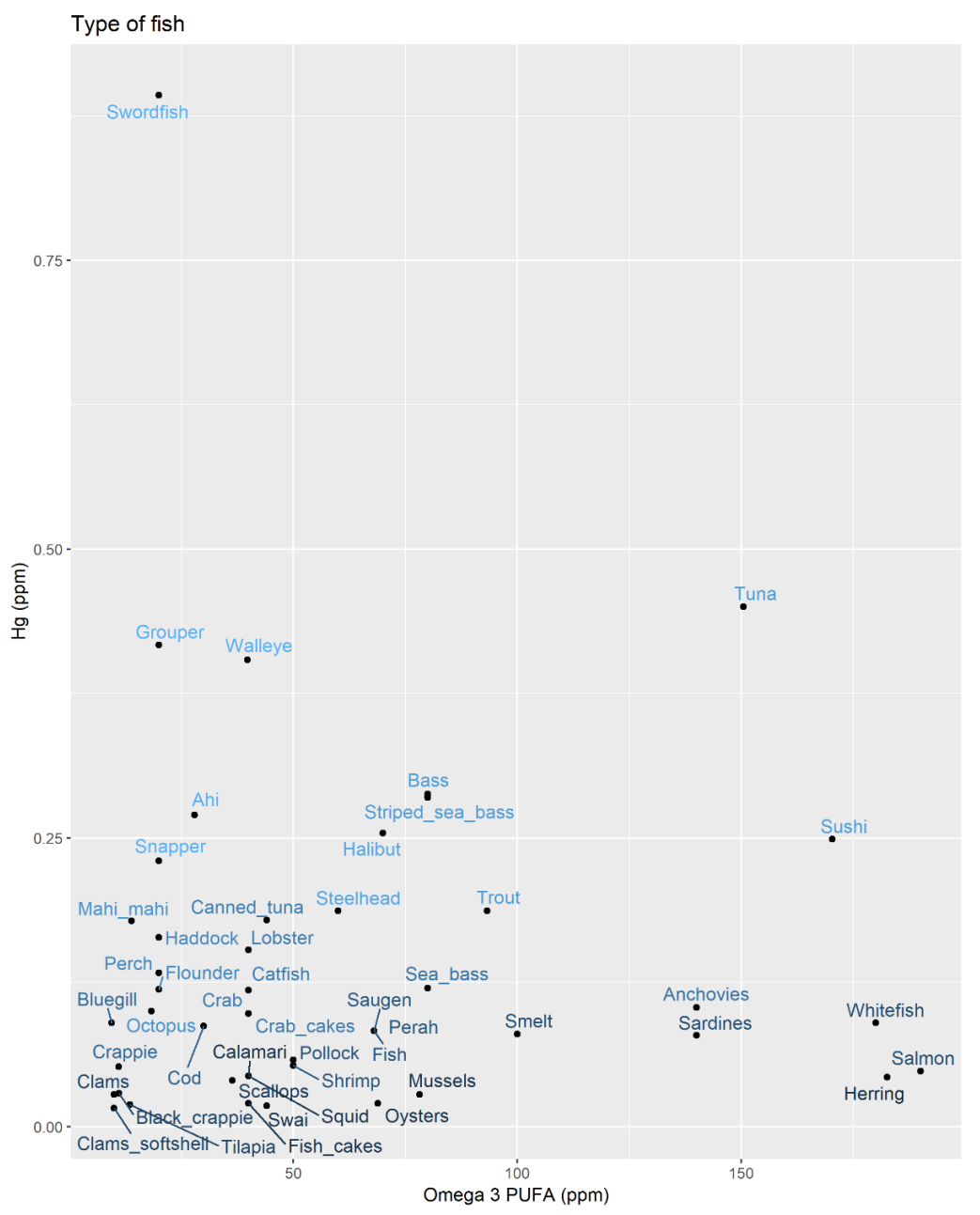

Figure 2. Mean mercury and omega-3 polyunsaturated fatty acid (PUFA) concentrations in seafood consumed by study participants. (brighter blue indicates higher mercury levels).

As shown in Table 3, among the $\sim 50 \%$ of the population who eat fish regularly, the log of the mean estimated annual consumption of neither mercury $(p=0.82)$ nor of omega-3 PUFA $(p=0.74)$ were associated with ALS risk.

Table 3. Analysis of relationship between fish-derived mercury, PUFA, and ALS risk.

\begin{tabular}{cccc}
\hline Among Regular Fish Consumers & $\begin{array}{c}\text { Controls } \\
\boldsymbol{n}=\mathbf{1 6 0}\end{array}$ & $\begin{array}{c}\text { ALS Cases } \\
\boldsymbol{n}=\mathbf{8 2}\end{array}$ & $\begin{array}{c}\text { Univariate } \\
\boldsymbol{p} \text {-Value }\end{array}$ \\
\hline Estimated fish-derived consumption of: & $\log$ mean (SD) & $\log$ mean (SD) & \\
Mercury & $2.55(0.44)$ & $2.53(0.40)$ & 0.82 \\
PUFA & $5.33(0.45)$ & $5.31(0.43)$ & 0.74 \\
\hline
\end{tabular}

Contrary to our hypothesis, our estimate of the annual mercury intake via seafood was not related to income (Figure 3).

Figure 4 shows a Bayesian Kernal Mixture Model of income, intake of mercury, and omega-3 PUFA in relation to ALS risk. Mercury and omega-3 PUFA intakes did not show a relationship with ALS risk, hovering around 0.0. The increased risk associated with income did not vary by 25th, 50th, and 75th quartiles of mercury and omega-3 PUFA intake. 


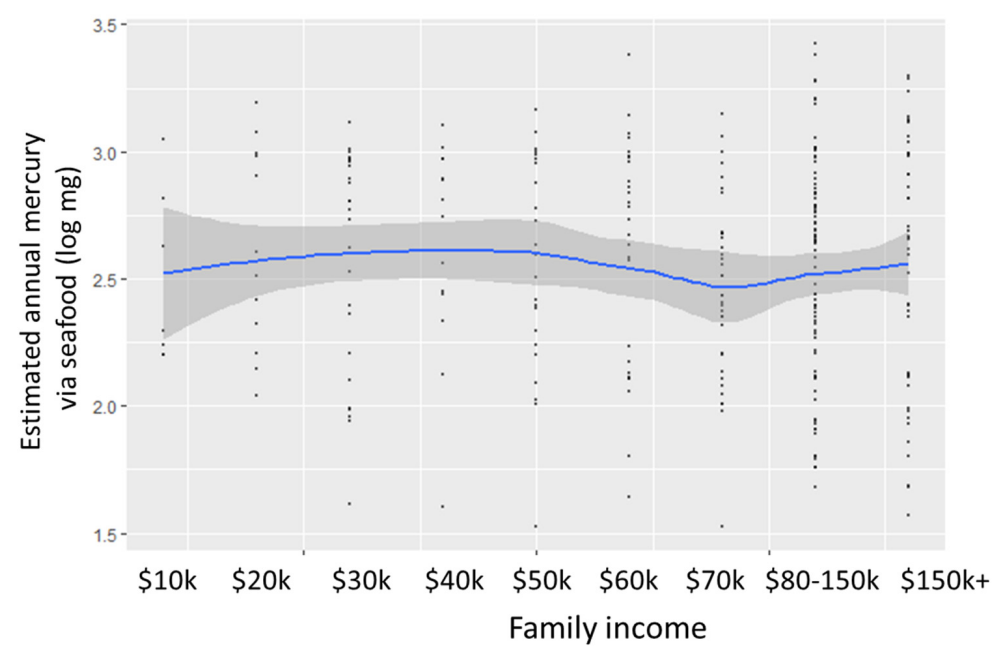

Figure 3. Annual mercury intake by family income.

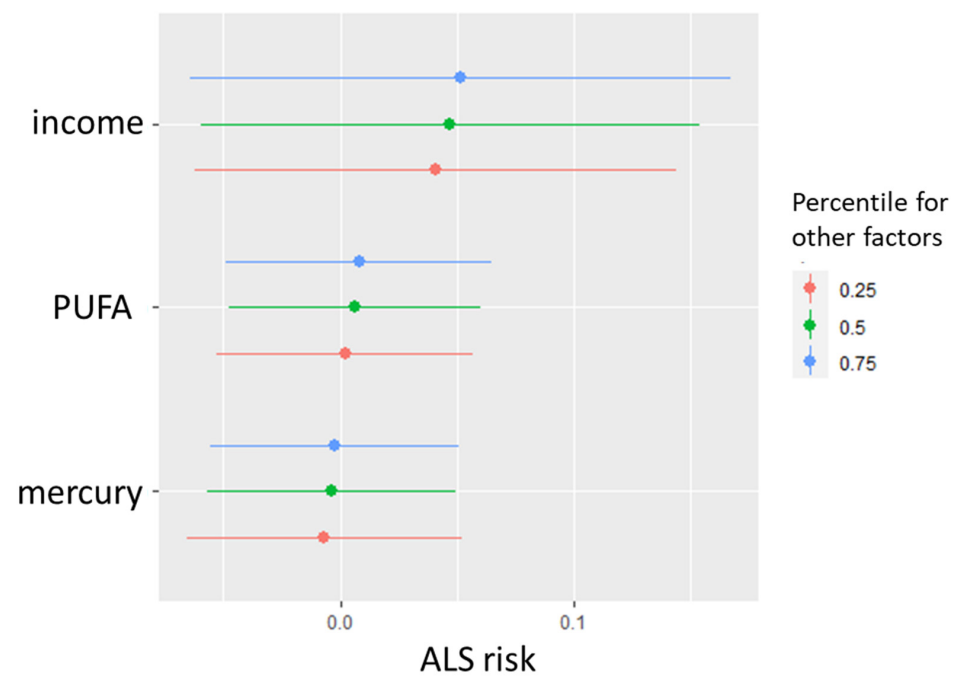

Figure 4. Relationship between income and both estimated mercury and omega-3 PUFA intakes via fish and seafood.

\section{Discussion}

Previous studies support the association between ALS diagnosis and mercury levels in biomarkers. In Japan, participants with ALS had greater hair mercury concentrations than control participants [30]. In our prior work in Northern New England, U.S. participants with ALS had higher toenail mercury levels than controls, adjusting for age and sex [2]. We replicated this relationship using nails from nationally distributed U.S. cohorts [3]. However, these studies did not identify the source of this mercury exposure.

Within the nationally distributed Sister Study cohort of controls without neurodegenerative illness, higher income was positively associated with toenail mercury biomarker levels [3]. Similarly, the National Health and Nutrition Examination Survey (NHANES) of the general population 1999-2004 found elevated blood mercury levels in women were associated with higher income and eating more fish [31]. Because high trophic-level fish that have more mercury, such as swordfish, are costly in the U.S, the current project tested the hypothesis that seafood consumption habits are a socioeconomically related risk factor for ALS.

In the U.S. population, fish consumption is the primary source of mercury $[5,6,31]$. In a San Francisco study of mercury biomarker levels over time $(n=67)$, higher blood mercury levels correlated with swordfish consumption and decreased significantly after 
they stopped eating fish $(p<0.0001)$ [9]. Nevertheless, our study has corroborated the findings of Parkin Kullman and Pamphlett from an international online questionnaire that similarly did not find a relationship between risk of ALS and either seafood consumption or seafood-based mercury intake [32]. One explanation for these findings is that dietary recall is notoriously difficult, and accurately listing the frequency and species of fish consumed can be challenging. Seafood species choice in the grocery store may be determined by the price-per-pound that week and the appearance or other factors such as a fresh appearance, rather than species, and thus misclassification may be influencing the results of these studies towards the null.

Other sources of mercury exposure are also possible risk factors. Parkin Kullman and Pamphlett also assessed mercury amalgam dental fillings as an alternative source of mercury, but did not find an association with ALS [32]. Mercury is emitted into the air by some industrial activities, yet Palacios et al. found limited evidence of an association between airborne mercury reported to the U.S. EPA National Air Toxics Assessment (NATA) and incidence of the neurodegenerative disease Parkinson's in a prospective cohort of female nurses (HR 1.33 95\% CI 0.98-1.79) [33]. Anti-aging and skin-lightening skin-care products that contain mercury are used and sold in the U.S. illegally, marketed as creams to combat age spots and wrinkles [34].

It is possible that other unmeasured dietary components could be modifying the absorption of mercury via the gastrointestinal tract. In vitro studies demonstrate that absorption of methylmercury through the intestinal epithelium is significantly reduced by cells secreting mucus and by l-cysteine, bile salts, and food components [35]. The intestinal microbiome is also capable of changing the methylation status of mercury, which could also impact the bioavailability and toxicity [36]. A study of twins with discordant socioeconomic deprivation status showed significant differences in the composition of their fecal 16s rRNA microbiomes [37]. Such influences could dissociate our calculated mercury intake via seafood from the absorbed neurotoxic dose, making it a poor estimate of exposure. Similarly, the trace element selenium may also reduce the bioavailability of methylmercury, but because of geographic variation, the selenium-to-mercury molar ratios for the tissue of fish species varies widely [7]. Selenium is also present in other dietary components, making it difficult to estimate its exposure levels using our questionnaire data.

Longitudinal analysis of over one million participants found that greater omega-3 PUFA intake was associated with a reduced risk for ALS [4]. However, our questionnairebased estimation of omega-3 PUFA consumption via seafood was not associated with ALS. Again, this may be due to the amount of misclassification in self-reported past fish consumption for species and frequency. We also addressed the hypothesis that PUFA would counteract mercury with a negative interaction; however, our data as shown in Figure 4 does not show variation in the mercury-ALS relationship with increasing PUFA quartiles. Using exposure biomarkers, several other studies have found no correlation between omega-3 PUFA and ALS and Alzheimer's disease neurological impairment. Notably, O'Reilly et al. used gas liquid chromatography to assess PUFA levels in prediagnostic plasma samples archived from large cohorts (with $n=275$ ALS patients identified). They found no association between total, $n-3$, and $n-6$ PUFA and subsequent ALS risk [38]. Omega-3 PUFA concentration in the blood was also not related to the incidence of dementia and Alzheimer's disease [39].

The statistically significant factors in our multivariable model of ALS risk were ALS family history and family income. Approximately $5-10 \%$ of ALS cases have inherited genetic susceptibilities to the disease, which is similar to the proportion we observed and conferred a $\sim$ four-fold increased risk [1]. We observed a positive association between family income and ALS risk. Similarly, a New Jersey study of $n=493$ ALS cases diagnosed in 2009-2011 found significantly elevated ALS relative risk (RR) of 1.37 (95\% CI 1.02-1.82) in the highest income quartile compared to the lowest [40]. The CDC's National Institute for Occupational Safety and Health (NIOSH) National Occupational Mortality Surveillance 
(NOMS) study also found that occupations associated with higher socioeconomic status (e.g., computer and mathematical, architecture and engineering, legal, and business operations) had elevated ALS mortality, after accounting for age, sex, and race [41]. Interestingly, with the multivariable model that included adjustment for family income, it was suggested that attending college or graduate school decreased risk, although statistical significance was not reached. The protective effect of longer duration of education was observed in a recent Chinese case-control study ( $\mathrm{OR}=0.1895 \% \mathrm{CI} 0.08-0.43$ ) [42]. It is possible that socioeconomically related behavioral risk factors or exposures could modify ALS risk, and future investigation into these factors is warranted.

Limitations of this project include the use of self-reported dietary choices of seafood types and frequencies (e.g., weekly, monthly, and annual). We asked ALS patients to recall their typical fish and seafood consumption 6 months before their ALS diagnosis and asked controls to report on a similar timeframe. These details are difficult to accurately record retrospectively, resulting in some misclassification of our mercury and omega-3 PUFA exposure estimation. Moreover, mercury concentrations for each seafood item are highly variable [14]. Our study included $n=165$ ALS cases and 2:1 matched controls from the Northern New England and Ohio regions, which may not be generalizable to other populations. We contacted controls from these regions by mail, and the $10 \%$ participation rate is a weakness of this approach. Nonetheless, our results are consistent with those of a recent international questionnaire study [32]. The random digit dialing approach obtained a similarly low response rate of $11 \%$ when it was used recently to obtain a populationbased control group for comparison with the National ALS Registry [43]. Ascertainment bias is unlikely to explain the association between higher income and increased risk ALS, because we observed an inverse relationship with education, with those attending graduate school at reduced ALS risk, compared to those who had a high school education (adjusted $p=0.019$ ).

\section{Conclusions}

In summary, our current work does not support fish and seafood consumption as an ALS risk factor using estimates of mercury, and we did not observe a counteracting effect of omega-3 PUFA content of the seafood. This finding leaves open compelling questions regarding the causal factors that mediate the relationship between ALS and income, as well as the source of the elevated nail and hair mercury biomarkers associated with ALS risk.

Supplementary Materials: The following are available online at https:/ / www.mdpi.com/article/ 10.3390/ijerph18094528/s1, Table S1: Mean mercury and omega-3 PUFA concentrations. Table S2: Seafood mercury and omega-3 PUFA mean concentration calculations for broad or vague participant responses.

Author Contributions: Conceptualization, A.S.A., H.I.H. and C.Y.C.; formal analysis, A.S.A. and H.I.H.; writing—original draft preparation, H.I.H. and A.S.A.; writing—review and editing, C.Y.C., W.G.B., E.W.S. and E.P.P. All authors have read and agreed to the published version of the manuscript.

Funding: This research was funded by the Hitchcock Foundation and Centers for Disease control (CDC)/Agency for Toxic Substances and Disease Registry (ATSDR) grant R01TS000288, entitled "Environmental risk factors for ALS: critical time periods and genetic interactions".

Institutional Review Board Statement: The study was conducted according to the guidelines of the Declaration of Helsinki, and approved by the Dartmouth Institutional Review Board.

Informed Consent Statement: Informed consent was obtained from all subjects involved in the study.

Data Availability Statement: Mean mercury and omega-3 PUFA concentrations are provided in Table S1.

Acknowledgments: We would like to thank the research staff and study participants who made this work possible. 
Conflicts of Interest: The authors declare no conflict of interest. The funders had no role in the design of the study; in the collection, analyses, or interpretation of data; in the writing of the manuscript, or in the decision to publish the results.

\section{References}

1. Martin, S.; Khaleifat, A.A.; Al-Chalabi, A. What causes amyotrophic lateral sclerosis? F1000Research 2017, 6. [CrossRef] [PubMed]

2. Andrew, A.S.; Chen, C.Y.; Caller, T.A.; Tandan, R.; Henegan, P.L.; Jackson, B.P.; Hall, B.P.; Bradley, W.G.; Stommel, E.W. Toenail mercury Levels are associated with amyotrophic lateral sclerosis risk. Muscle Nerve 2018, 58, 36-41. [CrossRef]

3. Andrew, A.S.; O’Brien, K.M.; Jackson, B.P.; Sandler, D.P.; Kaye, W.E.; Wagner, L.; Stommel, E.W.; Horton, D.K.; Mehta, P.; Weinberg, C.R. Keratinous biomarker of mercury exposure associated with amyotrophic lateral sclerosis risk in a nationwide U.S. study. Amyotroph Lateral Scler Front. Degener 2020, 21, 420-427. [CrossRef] [PubMed]

4. Fitzgerald, K.C.; O’Reilly, E.J.; Falcone, G.J.; McCullough, M.L.; Park, Y.; Kolonel, L.N.; Ascherio, A. Dietary omega-3 polyunsaturated fatty acid intake and risk for amyotrophic lateral sclerosis. JAMA Neurol. 2014, 71, 1102-1110. [CrossRef] [PubMed]

5. Cocoros, G.; Cahn, P.H.; Siler, W. Mercury concentrations in fish, plankton and water from three Western Atlantic estuaries. J. Fish Biol. 1973, 5, 641-647. [CrossRef]

6. Phillips, G.R.; Lenhart, T.E.; Gregory, R.W. Relation between trophic position and mercury accumulation among fishes from the Tongue River Reservoir, Montana. Environ. Res. 1980, 22, 73-80. [CrossRef]

7. Gribble, M.O.; Karimi, R.; Feingold, B.J.; Nyland, J.F.; O'Hara, T.M.; Gladyshev, M.I.; Chen, C.Y. Mercury, selenium and fish oils in marine food webs and implications for human health. J. Mar. Biol. Assoc. UK 2016, 96, 43-59. [CrossRef]

8. Chen, C.; Amirbahman, A.; Fisher, N.; Harding, G.; Lamborg, C.; Nacci, D.; Taylor, D. Methylmercury in marine ecosystems: Spatial patterns and processes of production, bioaccumulation, and biomagnification. Ecohealth 2008, 5, 399-408. [CrossRef]

9. Hightower, J.M.; Moore, D. Mercury levels in high-end consumers of fish. Environ. Health Perspect. 2003, 111, 604-608. [CrossRef]

10. Andrew, A.S.; Bradley, W.G.; Peipert, D.; Butt, T.; Amoako, K.; Pioro, E.P.; Tandan, R.; Novak, J.; Quick, A.; Pugar, K.D.; et al. Risk factors for amyotrophic lateral sclerosis: A regional United States case-control study. Muscle Nerve 2021, 63, 52-59. [CrossRef]

11. Costa, J.; Swash, M.; de Carvalho, M. Awaji criteria for the diagnosis of amyotrophic lateral sclerosis:a systematic review. Arch. Neurol. 2012, 69, 1410-1416. [CrossRef] [PubMed]

12. Ho, D.; Imai, K.; King, G.; Stuart, E. Matching as Nonparametric Preprocessing for Reducing Model Dependence in Parametric Causal Inference. Political Anal. 2007, 15, 199-236. [CrossRef]

13. Center for Food Safety and Applied Nutrition. Mercury Levels in Commercial Fish and Shellfish (1990-2012). Available online: https:/ / www.fda.gov/food/foodborneillnesscontaminants/metals/ucm115644.htm (accessed on 25 April 2020).

14. Karimi, R.; Fitzgerald, T.P.; Fisher, N.S. A quantitative synthesis of mercury in commercial seafood and implications for exposure in the United States. Environ. Health Perspect. 2012, 120, 1512-1519. [CrossRef] [PubMed]

15. Kristian, K.E.; Friedbauer, S.; Kabashi, D.; Ferencz, K.M.; Barajas, J.C.; O’Brien, K. A Simplified Digestion Protocol for the Analysis of Hg in Fish by Cold Vapor Atomic Absorption Spectroscopy. J. Chem. Educ. 2015, 92, 698-702. [CrossRef]

16. National Oceanic and Atmospheric Administration. Fisheries of the United States, 2017 Report. Available online: https://www. fisheries.noaa.gov / resource/document/fisheries-united-states-2017-report (accessed on 25 April 2020).

17. Sackett, D.K.; Cope, W.G.; Rice, J.A.; Aday, D.D. The Influence of Fish Length on Tissue Mercury Dynamics: Implications for Natural Resource Management and Human Health Risk. Int. J. Environ. Res. Public Health 2013, 10, 638-659. [CrossRef]

18. United States Environmental Protection Agency. FDA Fish Advice: Technical Information. Available online: https://www.epa.gov / fish-tech/epa-fda-fish-advice-technicalinformation (accessed on 25 April 2020).

19. Feng, C.H.-I. The tale of sushi: History and regulations. Compr. Rev. Food Sci. Food Saf. 2012, 11, 205-220. [CrossRef]

20. National Service Center for Environmental Publications. The National Survey of Mercury Concentrations in Fish. 2013. Available online: https: / / nepis.epa.gov/ (accessed on 25 April 2020).

21. Office of the United States Trade Representative. United States-Measures concerning the importation, marketing and sale of tuna and tuna products. Am. Soc. Int. Law 2013, 107, 192-199. [CrossRef]

22. Rodriguez, M.; Gutierrez, A.J.; Rodriguez, N.; Rubio, C.; Paz, S.; Martin, V.; Revert, C.; Hardisson, A. Assessment of mercury content in Panga (Pangasius hypophthalmus). Chemosphere 2018, 196, 53-57. [CrossRef]

23. Liebman, B.F. Omega medicine. Nutr. Action 2007, 34, 3-6.

24. United States Department of Agriculture. Full Report: Swai Fillet. 2018. Available online: https://ndb.nal.usda.gov/ (accessed on 25 April 2020).

25. Bellows, L.; Clifford, J.; Niebaum, K.; Bunning, M. Omega-3 Fatty Acids. 2015. Available online: https:/ / extension.colostate.edu/ topic-areas/nutrition-food-safety-health/omega-3-fatty-acids-9-382/ (accessed on 25 April 2020).

26. Dieticians of Canada. Food Sources of Omega-3 Fats. 2016. Available online: https:/ / www.dietitians.ca/ (accessed on 25 April 2020).

27. Harvard School of Public Health. Omega-3 Fatty Acids: An Essential Contribution. 2018. Available online: https://www. hsph.harvard.edu/nutritionsource/what-should-you-eat/fats-and-cholesterol/types-of-fat/omega-3-fats/ (accessed on 25 April 2020).

28. 28. National Heart Foundation of Australia. Sources of Omega-3. 2015. Available online: https://www.heartfoundation.org.au/ (accessed on 25 April 2020). 
29. Bobb, J.F.; Valeri, L.; Claus Henn, B.; Christiani, D.C.; Wright, R.O.; Mazumdar, M.; Godleski, J.J.; Coull, B.A. Bayesian kernel machine regression for estimating the health effects of multi-pollutant mixtures. Biostatistics 2015, 16, 493-508. [CrossRef]

30. Mano, Y.; Takayanagi, T.; Ishitani, A.; Hirota, T. Mercury in hair of patients with ALS. Rinsho Shinkeigaku 1989, $29,844-848$. [PubMed]

31. Mahaffey, K.R.; Clickner, R.P.; Jeffries, R.A. Adult women's blood mercury concentrations vary regionally in the United States: Association with patterns of fish consumption (NHANES 1999-2004). Environ. Health Perspect. 2009, 117, 47-53. [CrossRef] [PubMed]

32. Parkin Kullmann, J.A.; Pamphlett, R. A Comparison of Mercury Exposure from Seafood Consumption and Dental Amalgam Fillings in People with and without Amyotrophic Lateral Sclerosis (ALS): An International Online Case-Control Study. Int. J. Environ. Res. Public Health 2018, 15, 2874. [CrossRef]

33. Palacios, N.; Fitzgerald, K.C.; Hart, J.E.; Weisskopf, M.G.; Schwarzschild, M.A.; Ascherio, A.; Laden, F. Particulate matter and risk of Parkinson disease in a large prospective study of women. Environ. Health 2014, 13, 80. [CrossRef]

34. USFDA. Mercury Poisoning Linked to Skin Products. Available online: https:/ /www.fda.gov/consumers/consumer-updates/ mercury-poisoning-linked-skin-products (accessed on 4 April 2021).

35. Vazquez, M.; Calatayud, M.; Velez, D.; Devesa, V. Intestinal transport of methylmercury and inorganic mercury in various models of Caco-2 and HT29-MTX cells. Toxicology 2013, 311, 147-153. [CrossRef]

36. Li, H.; Lin, X.; Zhao, J.; Cui, L.; Wang, L.; Gao, Y.; Li, B.; Chen, C.; Li, Y.F. Intestinal Methylation and Demethylation of Mercury. Bull. Environ. Contam. Toxicol. 2019, 102, 597-604. [CrossRef]

37. Bowyer, R.C.E.; Jackson, M.A.; Le Roy, C.I.; Ni Lochlainn, M.; Spector, T.D.; Dowd, J.B.; Steves, C.J. Socioeconomic Status and the Gut Microbiome: A TwinsUK Cohort Study. Microorganisms 2019, 7, 17. [CrossRef]

38. O’Reilly, E.J.; Bjornevik, K.; Furtado, J.D.; Kolonel, L.N.; Le Marchand, L.; McCullough, M.L.; Stevens, V.L.; Shadyab, A.H.; Snetselaar, L.; Manson, J.E.; et al. Prediagnostic plasma polyunsaturated fatty acids and the risk of amyotrophic lateral sclerosis. Neurology 2020, 94, e811-e819. [CrossRef]

39. Kroger, E.; Verreault, R.; Carmichael, P.H.; Lindsay, J.; Julien, P.; Dewailly, E.; Ayotte, P.; Laurin, D. Omega-3 fatty acids and risk of dementia: The Canadian Study of Health and Aging. Am. J. Clin. Nutr. 2009, 90, 184-192. [CrossRef] [PubMed]

40. Henry, K.A.; Fagliano, J.; Jordan, H.M.; Rechtman, L.; Kaye, W.E. Geographic Variation of Amyotrophic Lateral Sclerosis Incidence in New Jersey, 2009-2011. Am. J. Epidemiol. 2015, 182, 512-519. [CrossRef] [PubMed]

41. Beard, J.D.; Steege, A.L.; Ju, J.; Lu, J.; Luckhaupt, S.E.; Schubauer-Berigan, M.K. Mortality from Amyotrophic Lateral Sclerosis and Parkinson's Disease Among Different Occupation Groups-United States, 1985-2011. MMWR Morb. Mortal. Wkly. Rep. 2017, 66, 718-722. [CrossRef] [PubMed]

42. Lian, L.; Liu, M.; Cui, L.; Guan, Y.; Liu, T.; Cui, B.; Zhang, K.; Tai, H.; Shen, D. Environmental risk factors and amyotrophic lateral sclerosis (ALS): A case-control study of ALS in China. J. Clin. Neurosci. Off. J. Neurosurg. Soc. Australas. 2019, 66, 12-18. [CrossRef] [PubMed]

43. Bear, T.M.; Malek, A.M.; Foulds, A.; Rager, J.; Deperrior, S.E.; Vena, J.E.; Larson, T.C.; Mehta, P.; Horton, D.K.; Talbott, E.O. Recruitment of population-based controls for ALS cases from the National ALS Registry. Amyotroph. Lateral Scler. Front. Degener. 2021, 1-7. [CrossRef] 